\title{
The Impact of "Informer on Site" in Disaster Management
}

\author{
https://doi.org/10.3991/ijim.v11i3.6701 \\ Nik Nadian Nisa Nik Nazli \\ Universiti Sains Islam Malaysia, Malaysia \\ nadian_nisa13@yahoo.com \\ Sapora Sipon \\ Universiti Sains Islam Malaysia, Malaysia, \\ sapora@usim.edu.my \\ Asiah Ali \\ Universiti Sains Islam Malaysia, Malaysia, \\ asiah_ali2007@yahoo.com \\ Muhammad Nur Wafi Omar \\ Universiti Kuala Lumpur, Malaysia, \\ mromar.wafi@gmail.com
}

\begin{abstract}
Informer on site" is a smart phone application that provides a new channel for the community to raise complaint regarding a disaster in Malaysia. It is focused on disseminating information on disasters such as floods, landslides, typhoons, and haze within a short time in a reliable manner. This application could prove to be an effective and efficient tool to facilitate smooth communication and allows for faster emergency response. This paper discusses the the impact of "Informer on Site" in disaster management.
\end{abstract}

Keywords-application, disaster, smart phone

\section{$1 \quad$ Introduction}

Smart mobile phone is a medium that replaces television and radio to communicate, deliver, and co-ordinate information quickly to a large number of people [1]. It usually plays the most important role in disseminating information in effective way for disaster pre-warning such as flood, rainstorm and frost. Besides, it can ensure the safety of human beings and reducing losses during a disaster [2].

Usually, if a disaster occurs, communication infrastructure may become unavailable and it will be the cause of delays to offer the strategic assistance [3]. Thus, telecommunication is most important in disseminating emergency information. Nowadays, the use of mobile technology in creating applications using smart mobile phones has become popular and widely accepted. The high demand for mobile applications 
has attracted researchers to extend their studies on potential areas in mobile applications.

In the Indian Coast, for example, more than one hundred people were saved because a scientist, using his cell phone, managed to warn about an imminent serious tsunami caused by an 8.7 magnitude earthquake. Moreover, victims will easily survived in an effective and efficient way if they have more detailed information dissemination for the purpose of disaster pre-warning and for formulating emergency plans which help to reduce the possibility of injuries, deaths and other losses in a disaster $[2]$.

"Informer on Site" is a smart mobile phone application that provides a new channel for the community to raise complaint regarding a disaster in Malaysia. It allows interaction with other people and with the relevant authorities of an organization if a disaster happens [4].

"Informer on Site" focuses on disasters such as floods, landslides, typhoons, and haze. This application is intended in disseminating disaster information to the community through which the user can make a report about a disaster quickly and accurately, with attached video or photographs to and location map(s). For those who need the latest information in areas where there is a disaster, they can use this application as a reference to determine complaints and reports made by the public in regions hit by the disaster. This can help to reduce delays in disseminating information to the public if a disaster occurs [4].

This application could prove to be an effective and efficient tool to facilitate smooth communication and allows for faster emergency response. Smart mobile phones can replace television and radio to communicate, deliver, and disseminate information quickly to a large number of people. The advent of mobile apps for smart phones can help people save time and reduce costs and can facilitate effective cooperation between the public and the authorities for solving problems faced together. Without the cooperation of the public, it is difficult for the authorities to act constructively due to the lack of accurate information [5].

\section{Features}

This application has its own unique characteristics. It is the first-ever locationbased service with nationwide reporting handling coverage in Malaysia using smart mobile phone applications and a share-handling service to identify and alert the local authorities in charge. Reports and complaints by the users are also accompanied with pictures and location information so authorities can identify the place where the event occurred to resolve the matter quickly. The users can evaluate the level of satisfaction in terms of the service rendered via the quick action and response.by the authorities. This can help to save lives and prevent disasters from becoming worse. The cooperation of the users is for the authorities to perform their jobs more effectively and share information. [4]. 


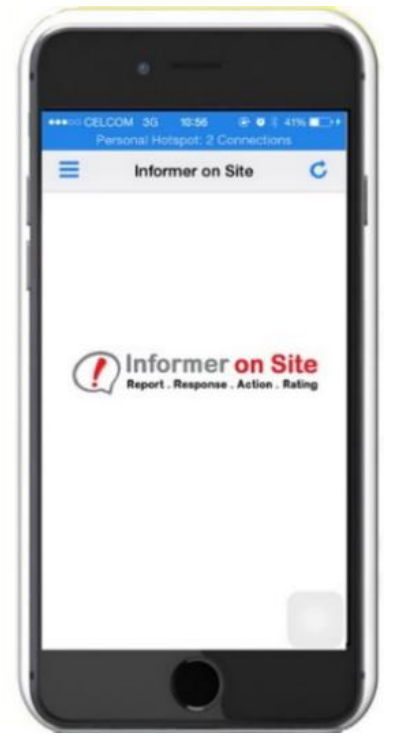

Fig. 1. Informer on Site Application

\section{Impact to Society}

"Informer on site" is a smart mobile phone application useful to Malaysian, especially flood-prone disaster. This channel is effective in providing information to the authorities by fast reporting disasters and more effective via smart phones [6]. Nowadays, it becomes a trend for Malaysians to use smart phone. Every layer of society no matter young or old, smart phone has become important and it is one of the fastest means of communication in spreading information within just a few seconds [7] [8]. Therefore, "Informer on site" can be as a medium to disseminate information, especially during emergencies such as disasters.

As an online channel, both user (society and rescuer) can update disaster information simultaneously. The updated information such as the reports or complaints will appear under the list of reports. This application gives valuable information to the related authorities. Public users can update the information anytime under the list of reports. Meanwhile, the community is able to check the progress of the reports or complaints via short messaging message (SMS) within a short time, thereby enabling the community to evaluate the satisfaction through this application.

In Malaysia, there are various ways for users to make emergency calls such as the complaints line, called the Malaysian Emergency Response Service (MERS) 999, created to enable the public to report emergencies happening anywhere in the country. MERS 999 is committed to implementing emergency communication. These emergency calls use fixed lines, and users need to dial 999 for emergency assistance such as fire, theft, and accidents. To avoid congestion on the line, the use of this application can help to continue to provide information to authorities without limits and barriers. 


\section{$4 \quad$ Impact to Rescuer}

Various disasters have been occurring in Malaysia such as floods, typhoons, landslides and haze. These events occur regardless of the season. Therefore, accurate and timely information from the public is urgently required to help authorities carry out their relief mission. The government agencies involved in disaster relief include the Department of Civil Defense (JPAM), the Malaysian Fire and Rescue Department (Rescue), the Royal Malaysian Police (PDRM) and private agencies such as MERCY and St. John Ambulance.

Through "Informer On Site", the government agencies involved in disaster relief can receive fast information from the informers and their actions will be more effective and faster compared than as usual. It is not only for disseminating and updating the disaster information, the application also provides a map where users can declare where the incident is occurring by using GPS coordinate in the maps and need no address to the subject place. The rescuer and authorities' body will continue to act according to the maps and GPS coordination that have been provided. The accuracy of incident venue is most important in order not late reaching the incident places.

While in a chaos situation, it is troublesome to answer all questions regarding the disaster situation. Therefore, this application gives a good solution to answers all questions as soon as possible through online [9]. In addition, rescuer can report the incidents through online application thus, the other users will see the incident progress. This application can also be a medium of information between the Fire Bridge, and civil defense in resolving those problems matters. The synergy between this bodies may provide fast action with and effectively way.

The mobile application for smart phones advent helping people to save time and to reduce the operating costs and can facilitate effective cooperation between the public and the authorities in solving the problems and faced together [9]. This mobile application also provides accurate information, fast action and superior result.

Various disasters have been occurring in Malaysia such as floods, typhoons, landslides and haze. These events occur regardless of the season. Therefore, accurate and timely information from the public is urgently required to help authorities carry out their relief mission. The government agencies involved in disaster relief include the Department of Civil Defense (JPAM), the Malaysian Fire and Rescue Department (Rescue), the Royal Malaysian Police (PDRM) and private agencies such as MERCY and St. John Ambulance.

Through "Informer On Site", the government agencies involved in disaster relief can receive fast information from the informers and their actions will be more effective and faster compared than as usual. It is not only for disseminating and updating the disaster information, the application also provides a map where users can declare where the incident is occurring by using GPS coordinate in the maps and need no address to the subject place. The rescuer and authorities' body will continue to act according to the maps and GPS coordination that have been provided. The accuracy of incident venue is most important in order not late reaching the incident places.

While in a chaos situation, it is troublesome to answer all questions regarding the disaster situation. Therefore, this application gives a good solution to answers all 
questions as soon as possible through online [10]. In addition, rescuer can report the incidents through online application thus, the other users will see the incident progress. This application can also be a medium of information between the Fire Bridge, and civil defense in resolving those problems matters. The synergy between this bodies may provide fast action with and effectively way.

The mobile application for smart phones advent helping people to save time and to reduce the operating costs and can facilitate effective cooperation between the public and the authorities in solving the problems and faced together. This mobile application also provides accurate information, fast action and superior result.

\section{Conclusion}

The "Informer on Site" application conveys information on disasters with site pictures and location using smart phones. It can assist the public in making complaints and reports quickly and in obtaining immediate feedback from the authorities. Besides assisting the public, it also helps the authorities to perform their duties more quickly. It has been developed and tested with users. The success in solving disaster issues is dependent on the effectiveness of the response at the scene and, more importantly, in collaboration with various government agencies, the private sector, NGOs, and community groups. There is a need to analyze information dissemination to ensure that warning information can be spread to every person without short delay times in a reliable manner. Using Informer on Site application it is the best way in disseminate emergency information for society in Malaysia, especially. Application informer on site will be established to disseminate emergency information timely and accurately under various circumstances.

\section{Acknowledgment}

This research was conducted with a grant awarded by the Ministry of Higher Education Malaysia (USIM/LRGS(UUM)/FKP/ULUM/34/50112) entitled "Flood Management Impact Reduction and Relief: - Flood Relief Management, A Psychosocial Dynamic Model for Well Being."

\section{$7 \quad$ References}

[1] Nik Nadian Nisa Nik Nazli, Sapora Sipon, Norita MD Norwawi (2015). One stop centre for disaster training information in smartphone platform: a mobile prototype. International Journal of Interactive Mobile Technologies. 10(1). 12-16.

[2] Zhang N, Huang H, Su B, Zhang B (2013) Analysis of different information dissemination ways for disaster pre-warning: A Case Study of Beijing. Proc 3rd Int Conf Multimedia Technol (ICMT 2013). Springer Berlin Heidelberg: 183- 192.

[3] Youhei Kawamura, Markus Wagner, Hyongdoo Jang, Hajime Nobuhara, Takeshi Shibuya, Itaru Kitahara, Ashraf M Dewan and Bert Veenendaal (2015) A Multimedia Data Visualization Based on Ad Hoc Communication Networks and Its Application to Disaster Man- 
agement. ISPRS International Journal of Geo-Information. 4, 2004-2018; https://doi.org/10.3390/ijgi4042004

[4] Nik Nadian Nisa Nik Nazli, Sapora Sipon, Norita MD Norwawi (2016). A prototype mobile application for informing disaster complaint - "Informer on Site". International Journal of Interactive Mobile Technologies. 10(1).75-77.

[5] Allen HG, Stanton TR, Di Pietro F, Moseley GL (2013) Social media release increases dissemination of original articles in the clinical pain sciences. PloS One 8(7): e68914. https://doi.org/10.1371/journal.pone.0068914

[6] Kaplan AM, Haenlein M (2010) Users of the world, unite! The challenges and opportunities of social media. Bus Horiz 53(1): 59-68. https://doi.org/10.1016/j.bushor.2009.09.003

[7] Kerrigan, Karen \& Keating, Raymond J. Saving time \& Money with mobile applications: a small business 'apps'ortunity. (2011). Internet: http://www.sbecouncil.org/uploads/Mobile APP Final Report SBE Council.pdf. Accessed August 25, 2016.

[8] Lengel RH, Daft RL (1988) The selection of communication media as an executive skill. Acad Manag Exec 2(3): 225-232. https://doi.org/10.5465/AME.1988.4277259

[9] Sattler DN, Larpenteur K, Shipley G (2011) Active shooter on campus: evaluating text and e-mail warning message effectiveness. J Homel Secur Emerg Manag 8(1) https://doi.org/10.2202/1547-7355.1826

[10] Shim JP, Varshney U, Dekleva S, Nickerson RC (2007) Wireless telecommunications issues: Cell phone TV, wireless networks in disaster management, ubiquitous computing, and adoption of future wireless applications. Commun Assoc Inf Syst 20: 442-456. 16. Katada T, Asada J, Kuwasawa

\section{$8 \quad$ Authors}

Nik Nadian Nisa Nik Nazli is Postgraduate Student at Universiti Sains Islam Malaysia (USIM), Nilai, Malaysia. She currently pursuing her PHd in Human Resource Management in USIM, Malaysia

Sapora Sipon is an associate professor in the Faculty of Leadership and Management, USIM. As a licensed counsellor and psychologist, she is an active columnist in a local newspaper and participating in numerous research, paper presentations and conferences locally and internationally. She has published several books related to her field of counseling and psychology. She has won several innovation and invention awards in her years with USIM. She is currently the project leader for this research grant under Ministry of Education Malaysia.

Asiah Ali is Postgraduate Student at Universiti Sains Islam Malaysia (USIM), Nilai, Malaysia. She currently pursuing her PHd in Human Resource Management in USIM, Malaysia

Muhammad Nur Wafi Omar is student at Universiti Kuala Lumpur, Malayia. He currently pursuing his in Islamic Finance, UNIKL, Malaysia

Article submitted 26 January 2017. Published as resubmitted by the authors 09 March 2017. 